\title{
Large de novo DNA deletion in a patient with sporadic neurofibromatosis 1 , mental retardation, and dysmorphism
}

Lucille M Kayes, Vincent M Riccardi, Wylie Burke, Robin L Bennett, Karen Stephens

\begin{abstract}
A mildly dysmorphic, mentally retarded male with neurofibromatosis 1 (NF1) was found to have a de novo deletion of chromosome 17. The deletion occurred on the paternally derived chromosome 17 as shown by the absence of a $D 17 S 73$ paternal allele. Densitometric analysis indicated that, in addition to the $D 17 S 73$ locus, the patient has only one copy of four other adjacent loci. The deletion involved the loci D17S120, NF1, D17S57, $D 17 S 115$, and $D 17 S 73$ and was estimated to encompass more than $380 \mathrm{~kb}$ of DNA. The deletion of the entire paternal NF1 allele argues strongly that this disorder is not caused by the action of an abnormal NF1 protein. The extent of the deletion suggests that the mental retardation and dysmorphism of this patient may result from a deletion involving both the NF1 gene and contiguous genetic material. ( $(\mathcal{M}$ Med Genet 1992;29:686-90)
\end{abstract}

Neurofibromatosis 1 (NF1) is a common autosomal dominant genetic disorder with an estimated prevalence of 1 in 3000. ${ }^{1}$ Subjects are considered to be affected if they have two or more diagnostic features including multiple neurofibromas, café au lait spots, axillary/ inguinal freckling, Lisch nodules of the iris, optic glioma, or distinctive osseous lesions. ${ }^{2}$ The disorder is characterised by a variable clinical presentation. The diagnostic features may commonly occur in association with other findings such as macrocephaly, bony abnormalities, learning disabilities, and an increased incidence of malignant tumours. ${ }^{3}$

The gene responsible for NF1 was mapped by genetic linkage analysis to chromosome $17 .^{45}$ Collaborative studies, summarised by Goldgar et $a l,{ }^{6}$ involving a large number of families have provided no evidence for locus heterogeneity. Data from genetic linkage mapping and direct molecular detection of NF1 gene mutations indicated that the same gene is responsible for the disorder in both sporadic and familial cases. ${ }^{7-9}$ The identification of two NF1 patients with balanced translocations facilitated localising the gene to chromosome 17 band q11.2 1011 and cloning of the gene. ${ }^{81213}$

While there are likely to be multiple complex mechanisms that account for the interand intrafamilial phenotypic variability of NF1, one important contributing factor may be the nature of the mutation of the NF1 gene.
To date, only a few mutations in the NF1 gene have been described. ${ }^{89121415}$ The search for mutations will probably be complicated by the large size of the gene, 13 to $15 \mathrm{~kb} \mathrm{cDNA}^{813}$ and the relative scarcity of large gene rearrangements. ${ }^{912}$

Characterisation of mutations in the NF1 gene may also provide clues to the molecular basis for the preferential mutation of the paternal NF1 allele. The mutation rate of the NF1 gene, estimated at $1 \times 10^{-4} /$ gamete/generation, is approximately 100-fold higher than most genes. ${ }^{116}$ In $92 \%$ of the cases of identified instances of new mutation $(n=25)$, it is the paternally derived NF1 allele that is mutated. ${ }^{151718}$ These data, in view of the slight or absent paternal age effect observed in this disorder, ${ }^{1619}$ suggest that a sex specific process, or genomic imprinting, may have a role in NF1 mutagenesis. ${ }^{1718}$

In this report we give the first molecular description of a mutation in an NF1 patient with mental retardation and dysmorphism. The mutation is a large de novo deletion of the paternally derived chromosome 17 that appears to encompass an entire NF1 allele and additional flanking DNA.

\section{Materials and methods}

PATIENT

The proband was brought to our attention by VMR after cytogenetic analysis suggested a possible deletion involving chromosome band $17 q 11.2$, the location of the NF1 gene. All other chromosomes appeared unaltered.

The proband is a 20 year old Caucasian male. The pregnancy was uneventful apart from spotting at eight months; delivery at 38 weeks was spontaneous and normal. Hypotonia, slight dysmorphism, and absence of the coccyx were noted at birth, and developmental delay was observed in infancy and early childhood. NF1 was diagnosed at 3 years of age on the basis of multiple café au lait spots, axillary freckling, and a neurofibroma on the right arm. On his most recent formal developmental evaluation aged 11 years, he was reported to have an IQ of 46 . The patient attended special education classes until the age of 18 , and currently participates in a work-training programme that includes employment. On examination by WB at 18 years of age, the proband was mildly dysmorphic, with coarse facial features, prominent brow, receding mandible, large normally placed ears. and large hands. He had a pleasant and coopt_ative personality. 
Genotypes of the family and densitometric analysis of the patient.

\begin{tabular}{|c|c|c|c|c|c|c|c|c|}
\hline \multirow[b]{2}{*}{ Locus* } & \multirow[b]{2}{*}{ Marker $\dagger$} & \multirow[b]{2}{*}{ Enzyme } & \multicolumn{3}{|c|}{ Genotype } & \multirow{2}{*}{$\begin{array}{l}\text { Band density } \\
\text { of son§ }\end{array}$} & \multirow{2}{*}{$\begin{array}{l}\text { Marker } \\
\text { reference }\end{array}$} & \multirow[b]{2}{*}{ Source|| } \\
\hline & & & Mother & Father & Son & & & \\
\hline $\begin{array}{l}D 17 S 58 \\
D 17 S 33 \\
D 17 S 82 \\
C R Y B 1 \\
D 17 S 120 \\
N F 1 \\
D 17 S 115 \\
D 17 S 57 \\
D 17 S 73 \\
D 17 S 54 \\
D 17 S 36\end{array}$ & $\begin{array}{l}\text { EW301 } \\
\text { HHH202 } \\
\text { TH17.19 } \\
\text { Beta 8-2 } \\
\text { VAW215R3 } \\
\text { P5 } \\
\text { VAW210M2 } \\
\text { EW206 } \\
\text { EW207 } \\
\text { EW203 } \\
\text { L946 }\end{array}$ & $\begin{array}{l}\text { BglII } \\
\text { RsaI } \\
\text { BglII } \\
\text { MspI } \\
\text { TaqI } \\
\text { TaqI } \\
\text { MspI } \\
\text { MspI } \\
\text { BglII } \\
\text { BglII } \\
\text { BglII }\end{array}$ & $\begin{array}{l}22 \\
12 \\
22 \\
11 \\
12 \\
22 \\
12 \\
22 \\
22 \\
12 \\
12\end{array}$ & $\begin{array}{l}22 \\
11 \\
12 \\
12 \\
11 \\
12 \\
12 \\
22 \\
11 \\
11 \\
22\end{array}$ & $\begin{array}{r}22 \\
12 \\
12 \\
11 \\
-1 \\
-2 \\
-1 \\
-2 \\
-2 \\
12 \\
22\end{array}$ & $\begin{array}{c}100 \% \pm 6 \\
45 \% \pm 1 \\
33 \% \pm 1 \\
56 \% \pm 2 \\
48 \% \pm 10 \\
40 \% \pm 3\end{array}$ & $\begin{array}{r}24 \\
25 \\
26 \\
24 \\
24 \\
8 \\
24 \\
24 \\
24 \\
24 \\
7\end{array}$ & $\begin{array}{l}\text { ATCC } \\
\text { ATCC } \\
\text { R White } \\
\text { ATCC } \\
\text { ATCC } \\
\text { F Collins } \\
\text { ATCC } \\
\text { ATCC } \\
\text { ATCC } \\
\text { D Barker } \\
\text { CRI }\end{array}$ \\
\hline
\end{tabular}

* As designated by the Human Gene Mapping Library.

† Marker loci are listed in order of position from proximal $17 \mathrm{p}$ to proximal $17 \mathrm{q}$ as determined by Goldgar et al, ${ }^{6}$ Fountain $e t a l,{ }^{27} 28$ and Fain et al. ${ }^{24}$ Unique positions for $C R Y B 1$ and D17S115 are not known (see Discussion, fig 3).

$\ddagger$ Restriction endonuclease used to show the polymorphism.

$\S$ Expressed as the percent of controls, as described in Materials and methods section.

ATCC = American Type Culture Collection, Rockville, MD; CRI = Collaborative Research Inc, Waltham, MA 02154

Skin manifestations included more than 10 café au lait spots of $1.5 \mathrm{~cm}$ or greater distributed randomly over the trunk, upper arms, and legs. In addition, more than 50 cutaneous neurofibromas, ranging from 2 to $25 \mathrm{~mm}$ in size, were located randomly over the trunk and extremities; the largest of these was a plexiform neurofibroma on the right arm. Magnetic resonance imaging of the head at 18 years was normal.

Independent examination of the parents by VMR and WB showed no diagnostic features or borderline findings of NF1; the educational and career achievements of the parents suggest average, or higher, IQ levels. The patient has one unaffected brother who was not studied.

\section{DNA STUDIES}

Venous blood from the patient and his parents was obtained with appropriate consent. Lymphoblastoid cell lines were established by transformation of white blood cells with Epstein-Barr virus. ${ }^{20}$ DNA was purified from whole blood and immortalised lymphoblasts, ${ }^{21}$ transferred by $\mathrm{NaOH}$ to Zetabind membrane (AMF Cuno, Meriden, CT), and hybridised to radiolabelled DNA probes, ${ }^{22}$ as previously described. ${ }^{23}$

\section{COPY NUMBER DETERMINATION}

To differentiate between homozygosity or hemizygosity for loci in the NF1 gene region in the proband, two autoradiographs from independently prepared and hybridised Southern blot membranes were subjected to densitometric analysis. One membrane contained DNA purified from lymphoblastoid cell lines and the other DNA purified from both lymphoblastoid cell lines and from whole blood. DNA probes for two loci were simultaneously hybridised to the DNA on each Southern membrane; one locus was near/in the NF1 gene and the second locus was on a different chromosome and was used to control for differences in DNA concentration between samples. In most cases, restriction enzymes were chosen that could show a polymorphism at the NF1 regional locus to determine the alleles and their density simultaneously. One of three control loci were used: L112 (D1S52), P166 (D2S30), or L917 (D7S15). ${ }^{23}$ Densitometry was performed using a Hoefer GS300 densitometer with Macintosh II interface.

The ratio of the density of the fragment(s) homologous to the NF1 regional locus compared to the density of the fragment(s) homologous to the control locus in the same lane was calculated for the patient's DNA and the DNA of a least one unaffected, unrelated control on the same autoradiograph. Controls homozygous for the same allele as the proband were used whenever possible. The density ratio for the proband divided by the density ratio of the control expressed as a percent is defined as the band density. Band density values given in the table are the average of duplicate experiments.

\section{Results}

DELETION OF THE PATERNAL CHROMOSOME

As shown in fig 1 , the patient did not inherit a paternal allele for locus D17S73. The band

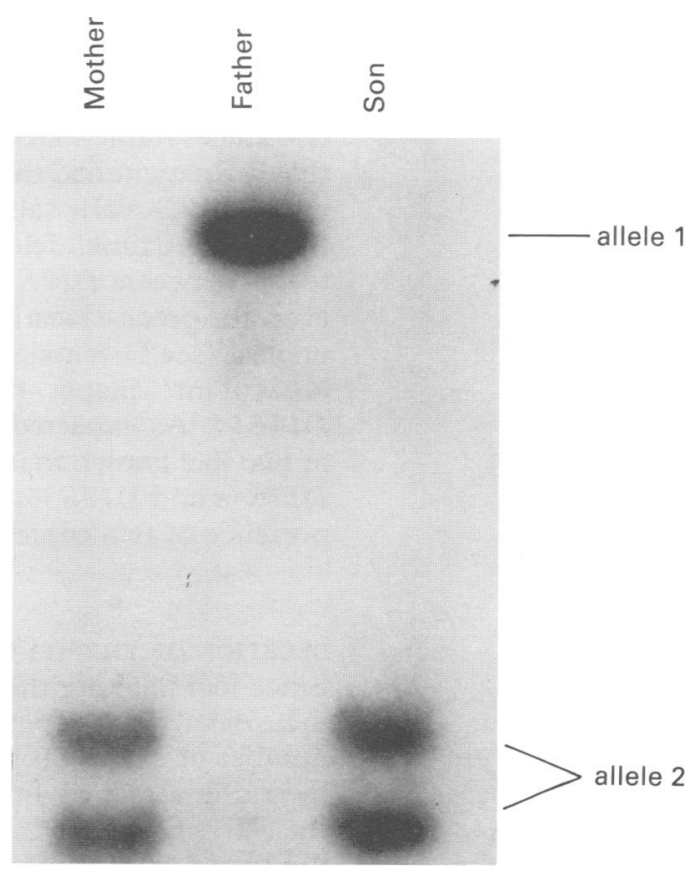

Figure 1 Absence of a paternal allele for D17S73. An autoradiograph of a Southern membrane of BglII digested DNA purified from peripheral blood and hybridised to the probe EW207 (D17S73). The alleles for each family member are indicated. Bands homologous to a simultaneously hybridised marker, used to control for differences in DNA concentration between lanes, are not shown on the photograph. 
density of the patient's maternal allele 2 was only $40 \%$ that observed for controls (table), consistent with hemizygosity at this locus. The unaffected parents are D17S73 homozygotes as judged by comparable allele densities observed for the parents and for unrelated, unaffected controls (table, Materials and methods). No evidence for incorrect paternity was observed when the family was studied with multiple loci flanking the NF1 gene (table) and six additional loci of high polymorphic information content including L586 (D2S39), L22 (D2SW21), L45 (D5S61), L386 (D10S12), L84 (D16S43), and 3'HVR (D16S85) (data not shown). ${ }^{232}$ Together, these data show that the patient carries a deletion involving the paternal D17S73 locus, known to be tightly linked and located q distal to the NF1 gene.

\section{EXTENT OF THE DELETION}

To approximate the limits of the deletion, we identified the closest loci for which the patient was heterozygous that flanked the deleted D17S73 locus. The genotypes for 10 loci known to flank the D17S73 locus were determined for the patient and his parents (table). The parents have two copies of all loci tested; autoradiographic band densities were equivalent to the densities observed for unrelated, unaffected controls (data not shown). The patient is heterozygous for two loci centromeric to the deletion, D17S82 and D17S33, and for one locus telomeric, D17S54. Therefore, the deleted region lies between $D 17 S 82$ and D17S54.

To define the limits of the deletion, we determined the copy number by densitometric analysis for loci between D17S82 and D17S54. The patient is hemizygous for D17S120, D17S57, and D17S115; the allele band density was one half that expected for the presence of two alleles (table). Densitometry also indicated that the patient had two copies of the $\beta$ crystallin gene (CRYB1, table). Therefore, the centromere proximal deletion breakpoint appears to lie between $D 17 S 120$ and $C R Y B 1$; however, the precise location of the CRYB1 gene is unclear (see Discussion). The q distal deletion breakpoint maps between $D 17 S 73$ and D17S54. As expected, densitometric analysis of two loci known to map outside the deletion, D17S58 and D17S36, were consistent with the presence of two copies (table).

\section{DELETION OF THE NF1 GENE}

Since loci flanking the NF1 gene were known to be deleted in the patient, we investigated the number of copies of the NF1 gene by densitometric analysis of fragments homologous to the NF1 cDNA P5 that maps near the $3^{\prime}$ end of the gene. ${ }^{8}$ The autoradiograph in fig 2 shows that the bands homologous to the NF1 cDNA $\mathrm{P5}$ are at reduced density in the patient compared to those of his unaffected parents. The similar densities of bands homologous to the chromosome 7 control marker $\mathrm{L} 917$ for all family members indicate that near equal

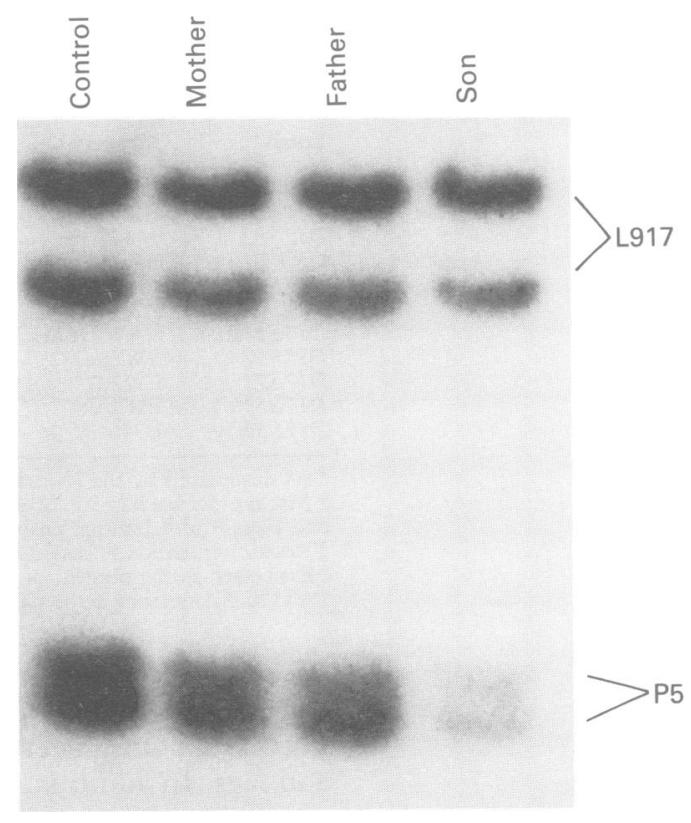

Figure 2 Hemizygosity for NF1 cDNA P5. A Southern membrane of MspI digested DNA from peripheral blood was simultaneously hybridised to the NF1 cDNA P5 and L917 (D7S15), a marker on chromosome 7 used to control for DNA concentration differences between lanes. Fragments homologous to each marker are indicated on the autoradiograph. DNA samples: lane 1, unrelated, unaffected control, lane 2, unaffected mother, lane 3, unaffected father, and lane 4, NF1 affected son.

amounts of DNA were loaded in each lane. Densitometric analysis and calculation of allele band density showed that the proband was hemizygous for the $3^{\prime}$ region of the NF1 gene homologous to P5 (table).

\section{Discussion}

We have identified a large de novo deletion of chromosome 17 encompassing the NF1 gene in a patient with neurofibromatosis type 1 . As summarised in fig 3 , the deletion involves a significant amount of genetic material telomeric to and contiguous with the NF1 gene. The 3 ' end of the NF1 gene homologous to the cDNA P5 is deleted, along with three loci located q distal to the NF1 gene, D17S115, $D 17 S 57$, and D17S73 (table). These data map the $\mathrm{q}$ distal deletion breakpoint outside the NF1 gene and between the loci D17S73 and D17S54 (fig 3). Mapping the q proximal extent of the deletion is complicated by ambiguities in the order of probes in this region. The $q$ proximal deletion breakpoint clearly lies between $D 17 S 120$ and either CRYB1 or D17S82 (table, fig 3). Which of these latter two loci mark the $q$ proximal boundary of the deletion is unclear owing to a contradiction in the map position of the CRYB1 gene in hybrids generated by microcell fusion and chromosome mediated gene transfer. ${ }^{24}{ }^{30}$ While the anonymous locus $D 17 S 120$ is deleted (table) the precise physical relationship between this locus and the $5^{\prime}$ end of the NF1 gene is unknown. D17S120 most probably lies outside the NF1 gene since a microcell fusion hybrid endpoint lies between the cluster D17S33- 


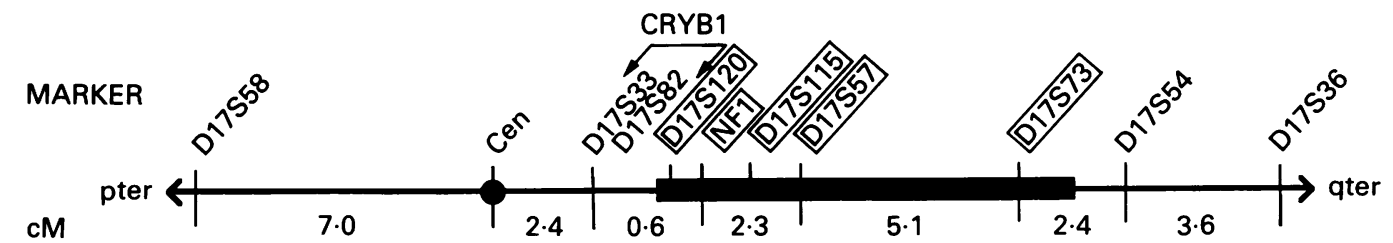

Figure 3 Map of de novo deletion of NF1 gene. Genetic map of loci flanking the NF1 gene which is transcribed in the direction from centromere to telomere. Bold line indicates extent of deletion; deleted loci are boxed. Number of $c M$ between loci from the sex averaged data of a collaborative study; positions of some loci determined from physical mapping. ${ }^{624} 27$ The two possible positions for CRYB1 are indicated by arrows (see Discussion); the unique position of D17S115 relative to D17S57 and D17S73 is not known.

D17S82-CRYB1-D17S120 and the $17 L 1$ locus that maps within the NF1 promoter region. ${ }^{132427}$

Current maps of the NF1 subchromosomal region of chromosome 17 can only provide an estimate of the size of the deletion. Genetically, the deletion ranges in size from a minimum of $7 \cdot 4 \mathrm{cM}$, the sex averaged distance from $N F 1$ to $D 17 S 73$, to a maximum of $10.4 \mathrm{cM}$, the sex averaged distance from D17S33 to D17S54. ${ }^{6}$ Physically, the borderline cytogenetic detectability of the deletion implies that $i_{i}$ is large in size (data not shown). A minimum physical distance is estimated at $380 \mathrm{~kb}$ of DNA, the approximate distance between the probes $17 L 1$ and IFIO both of which lie between D17S120 and D17S57, two loci which are deleted in our patient. ${ }^{82628}$ The true size of the deletion is expected to be greater than $380 \mathrm{~kb}$ since DNA beyond D17S57 is deleted (fig 3).

The deletion of the entire paternal NF1 allele in the patient strongly argues that the neurofibromatosis 1 disorder is not caused by the action of an abnormal NF1 protein. While many of the previously described NF1 mutations are known, or expected, to result in inactivation of the gene, in each case an abnormal truncated NF1 protein could have been produced. These mutations include intragenic deletions of $11,90,140$, and $190 \mathrm{~kb}$ of DNA, ${ }^{12}$ the two balanced translocations that were instrumental in identifying and cloning the gene, ${ }^{1011}$ an Alu element insertion, ${ }^{15}$ and several point mutations. ${ }^{14}$

While it is clear from haplotype analysis that new NF1 mutations preferentially occur in the paternally derived allele, ${ }^{1718}$ identifying the molecular nature of new mutations is just beginning. These studies will be important for investigating the molecular mechanism(s) that either increases the susceptibility of the paternally derived allele or protects the maternally derived allele from mutation. To date, only two molecularly characterised de novo NF1 mutations of known parental origin have been reported, this case, and a mutation caused by an Alu element insertion in a paternal NF1 allele. ${ }^{15}$ It appears unlikely that many other paternally derived new NF1 mutations will be caused by molecular mechanisms similar to these cases since both appear to be infrequent events; the NF1 gene is not deletion prone ${ }^{912}$ and de novo Alu insertions have not previously been described. ${ }^{15}$
Mapping NF1 deletions in clinically well characterised patients may identify genetic regions which, when deleted, result in specific NF1 or NF1 associated findings. To our knowledge, none of the previously described mutations are associated with mental retardation. ${ }^{9-121415}$ However, of the four deletions ${ }^{912}$ only the report of the $90 \mathrm{~kb}$ deletion provided information on the clinical features of the patient. ${ }^{9}$ It is interesting to speculate whether the mental retardation and dysmorphic phenotype of the proband might result from the deletion of gene(s) contiguous to, or embedded in, the NF1 gene. While genes contiguous to NF1 have yet to be identified, three genes are known to be embedded in a single large NF1 intron and transcribed from the opposite strand than the NF1 gene. ${ }^{1214}$ Based on our findings, it is important to screen additional NF1 patients with mental retardation for deletions that extend beyond the bounds of the NF1 gene. If such deletions occurred in a significant proportion of cases, this finding would have important implications for genetic counselling in NF1 families.

We thank Wendy Raskind and Laura Steinmann for their densitometry expertise, Francis $S$ Collins and Margaret $R$ Wallace for the P5 cDNA, David Barker for EW203, Ray White for TH17.19, and Collaborative Research Inc (Waltham, MA) for L22, L45, L84, L112, P166, L386, L586, and L917. This work was supported in part by the Stephen J Walker Memorial Award from the National Neurofibromatosis Foundation, Inc (KS), the Graduate School Research Fund of the University of Washington (KS), and the Saalam wa Saha Fund (VMR).

1 Crowe FW, Schull WT, Neel JV. A clinical, pathological, and genetic study of multiple neurofibromas. Springfield, Illinois: Charles C Thomas, 1956.

2 Stumpf S, Alksne JF, Annegers JF, et al. Neurofibromatosis Conference Statement. Arch Neurol 1988;45:575-8.

3 Riccardi VM, Eichner JE. Neurofibromatosis, phenotype, natural history and pathogenesis. Baltimore: Johns Hopkins University Press, 1986.

4 Barker D, Wright E, Nguyen $\mathrm{K}$, et al. Gene for von Recklinghausen neurofibromatosis is in the pericentromeric region of chromosome 17. Science 1987;236:1100-2

5 Seizinger BR, Rouleau GA, Ozelius LJ, et al. Genetic linkage of von Recklinghausen neurofibromatosis to the nerve growth factor receptor gene. Cell 1987;49:589-94.

6 Goldgar DE, Green P, Parry DM, Mulvihill JJ. Multipoin linkage analysis in neurofibromatosis type 1: an international collaboration. Am $\mathcal{F}$ Hum Genet 1989;44:6-12.

7 Stephens K, Riccardi VM, Rising M, et al. Linkage studies with chromosome 17 DNA markers in 45 neurofibromatosis 1 families. Genomics 1987;1:353-7.

8 Wallace MR, Marchuk DA, Andersen LB, et al. Type 1 neurofibromatosis gene: identification of a large transcrip disrupted in three NF1 patients. Science 1990;249:181-6. 
9 Upadhyaya M, Cheryson A, Broadhead W, et al. A $90 \mathrm{~kb}$ DNA deletion associated with neurofibromatosis type $1 . \mathcal{F}$ Med Genet 1990;27:738-41.

10 Schmidt MA, Michels VV, Dewald GW. Cases of neurofibromatosis with rearrangements of chromosome 17 bromatosis with rearrangements of chromosome 17

11 Ledbetter DH, Rich DC, O'Connell P, Leppert M, Carey JC. Precise localization of NF1 to $17 \mathrm{q} 11.2$ by balanced translocation. Am f Hum Genet 1989;44:20-4.

12 Viskochil D, Buchberg AM, Xu G, et al. Deletions and a translocation interrupt a cloned gene at the neurofibromatosis type 1 locus. Cell 1990;62:187-92.

13 Marchuk DA, Saulino AM, Tavakkol R, et al. cDNA cloning of the type 1 neurofibromatosis gene: complete sequence of the NF1 gene product. Genomics 1991;11:931-40.

14 Cawthon RM, Weiss R, Xu G, et al. A major segment of the neurofibromatosis type 1 gene: cDNA sequence, genomic neurofibromatosis type 1 gene: cDNA sequence, genom
structure, and point mutations. Cell 1990;62:193-201.

15 Wallace MR, Andersen LB, Sauline AM, Gregory PE, Glover TW, Collins FS. A de novo Alu insertion results in neurofibromatosis type 1 . Nature 1991;353:864-6.

16 Huson SM, Compston DAS, Clark P, Harper PS. A genetic study of von Recklinghausen neurofibromatosis in southeast Wales. I. Prevalence, fitness, mutation rate, and effect of parental transmission on severity. $f$ Med Genet 1989;26:704-11.

17 Stephens K, Kayes L, Riccardi VM, Rising M, Sybert VP, Pagon RA. Preferential mutation of the neurofibromatosis type 1 gene in paternally-derived chromosomes. Hum sis type 1 gene in pater

18 Jadayel D, Fain P, Upadhyaya M, et al. Paternal origin of new mutations in von Recklinghausen neurofibromatosis. Nature 1990;343:558-9.

19 Riccardi VM, Dobson CE II, Chakraborty R, Bontke C. The pathophysiology of neurofibromatosis. IX. Paternal age as a factor in the origin of new mutations. $\mathrm{Am} \mathcal{J} \mathrm{Med}$ Genet 1984;18:169-76.

20 Neitzel H. A routine method for the establishment of permanent growing lymphoblastoid cell lines. Hum Genet 1986;73:320-6.

21 Bell GI, Karam JH, Rutter WJ. Polymorphic DNA region adjacent to the $5^{\prime}$ end of the human insulin gene. Proc Natl Acad Sci USA 1981;78:5759-63.

22 Feinberg A, Vogelstein B. A technique for radiolabeling DNA restriction endonuclease fragments to high specific activity. Anal Biochem 1983;132:6-13.

23 Donis-Keller H, Green P, Helms C, et al. A genetic linkage map of the human genome. Cell 1987;51:319-37.

24 Fain PR, Goldgar DE, Wallace MR, et al. Refined physical and genetic mapping of the NF1 region on chromosom 17. Am $\mathcal{F}$ Hum Genet 1989;45:721-8.

25 White R, Nakamura Y, O'Connell $P$, et al. Tightly linked markers for the neurofibromatosis type 1 gene. Genomics 1987;1:364-7.

26 O'Connell P, Leach R, Cawthon RM, et al. Two NF1 translocations map within a 600 -kilobase segment of 17q11.2. Science 1989;244:1087-8.

27 Fountain JW, Wallace MR, Brereton AM, et al. Physical mapping of the von Recklinghausen neurofibromatosis region on chromosome 17. Am f Hum Genet 1989;44:58-

28 Fountain JW, Wallace MR, Bruce MA, et al. Physical mapping of a translocation breakpoint in neurofibromatosis. Science 1989;244:1085-7.

29 Jarman AP, Nickolls RD, Weatherall DJ, Clegg JB, Higgs DR. Molecular characterization of a hypervariable region downstream of the human alphaglobin gene cluster. $E M B O$ o 1986;5:1857-63.

30 Yagle MK, Parruti G, Xu W, Ponder BAJ, Solomon E. Genetic and physical map of the von Recklinghausen neurofibromatosis (NF1) region on chromosome 17. Proc Natl Acad Sci USA 1990;87:7255-9. 